\title{
PENERAPAN BUSINESS MODEL CANVAS UNTUK MENINGKATKAN PENJUALAN PERALATAN BELADIRI PADA TOKO DANIS
}

\author{
Yuda Aryasuta ${ }^{1)}$, Bima Cahya Putra ${ }^{2)}$ \\ ${ }^{1}$ Sistem Informasi, Fakultas Teknologi Informasi, Universitas Budi Luhur \\ ${ }^{1,2} \mathrm{Jl}$. Raya Ciledug, Petukangan Utara, Kebayoran Lama, Jakarta Selatan 12260 \\ E-mail : yudaaryasuta@gmail.com ${ }^{1)}$, bimo.cahyoputro@budiluhur.ac.id ${ }^{2}$ )
}

\begin{abstract}
Abstrak
Toko Danis ini merupakan suatu jenis usaha wirausaha kecil dan menengah yang bergerak dalam bidang penjualan peralatan beladiri. Masalah yang dihadapi oleh toko danis adalah susahnya dalam memasarkan produk produknya dan dalam pengelolaan data data yang ada. Sehingga sulit untuk memperkenalkan produk yang ada di toko danis tersebut dan juga pencatatan transaksi pembayaran dan penjualan alat-alat beladiri masih dengan tertulis dalam pembukuan sehingga sulit dalam mencari data, pada beberapa laporan sering terjadi ketidak-akuratan isi maupun data yang ada pada toko tersebut sehingga dalam pembuatan laporan masih harus diperbaiki. Dan pada tahap ini cara untuk meningkatkan penjualan ialah dengan menggunakan sebuah rancangan e-commerce yang dimana menggunakan sebuah metode business model canvas sehingga dapat meningkatkan penjulan peralatan beladiri pada toko danis adalah untuk mengembangkan penjualan barang yang hanya tidak dilakukan secara offline saja, sehingga pada penjualan toko danis dapat mengalami perubahan dan juga meningkatkan penjualannya.
\end{abstract}

Kata kunci: Business Model Canvas, E-Commerce, Peralatan Beladiri.

\section{PENDAHULUAN}

1.1. Latar Belakang

Seiring dengan berkembangnya teknologi informasi di era sekarang sudah banyak orang yang mengerti akan kegunaan dari sebuah komputer untuk membantu atau memudahkan dalam bekerja dan ada beberapa yang melakakukan usaha atau bisnis online yang sering dikenal dengan E-Commerce.

E-Commerce (Electronic Commerce) adalah sebuah sistem jual beli yang bersifat online, yang dimana calon pembeli hanya mengunjungi website yang dibuat oleh penjual dan melihat melihat produk yang di jual setelah itu memesannya secara online.

Dengan adanya E-Commerce dijaman sekarang sangat memudahkan dan menguntungkan orang lain untuk berbelanja dan membuka sebuah usaha. Dalam penelitian ini, obyek penelitian adalah Toko Danis yang dimana salah satu usaha yang bergerak di bidang penjualan alat-alat beladiri.

Jadi Pada Toko Danis akan dibuatnya sebuah website sistem penjualan, agar dapat memperoleh keuntungan yang maksimal sehingga pelanggan dapat membeli dimana pun dan kapan pun tanpa dibatasi waktu dan tempat.

\subsection{Tujuan Penulisan}

Dalam penulisan penelitian ini penulis memiliki beberapa tujuan yaitu:

a. Memudahkan pelanggan mengetahui produk apa saja yang ada pada Toko Danis.

b. Memudahkan pelanggan mengetahui Promosi apa saja yang ada di Toko Danis sehingga dapat meningkatkan penjualan.

\subsection{Manfaat Penelitian}

Manfaat dari penulisan penelitian ini adalah diharapkan dapat meningkatkan keuntungan kepada penjual dan dapat memudahkan konsumen dalam proses jual-beli produk tanpa dibatasi waktu dan tempat, dan membantu konsumen mengetahui informasi-informasi yang ada pada penjual.

\subsection{Masalah}

Berdasarkan latar belakang yang telah dijelaskan di atas, maka yang menjadi permasalahan yang dihadapi oleh Toko Danis, diantaranya sebagai berikut:

a. Pemasaran produk dan Transaksi pelanggan masih ada batasan waktu dan tempat.

b. Hanya ada kendala mempromosikan produk baru dan lama karena tidak memiliki data customer.

\section{PENELITIAN SEBELUMNYA}

2.1. APLIKASI E-COMMERCE PENJUALAN SOUVENIR PERNIKAHAN PADA TOKO "XYZ" Penerbit Edi Haerulah, Sri Ismiyatih. Yang Dipublikasikan Pada Jurnal.

Penjualan adalah penjualan barang dagangan sebagai usaha pokok bagi perusahaan tersebut yang biasanya dilakukan secara teratur. Penjualan adalah salah satu sumber pendapatan perusahaan, semakin besar penjualan maka semakin besar pula pendapatan yang di peroleh perusahaan tersebut. [1] 
2.2. Sistem Penjualan Berbasis Web ( E-Commerce ) Pada Tata Distro Kabupaten Pacitan. Penerbit Hastanti, R. P., Eka, B., Indah, P., \& Wardati, U. Yang Dipublikasikan Pada Jurnal.

E-Commerce adalah Pembelian, penjualan dan pemasaran barang serta jasa melalui sistem elektronik. Seperti radio, televisi dan jaringan computer atau internet.[2]

\subsection{Business Model Canvas (BMC)}

BMC adalah suatu model analisis yang menjelaskan suatu ide bagaimana suatu organisasi atau perusahaan meciptakan, memberikan, dan menangkap nilai yang dimiliki oleh suatu organisasi ataupun perusahaan tersebut.[3]

\subsection{Analisa Business Model Online Ride-Sharing} (Studi Kasus Uber di Indonesia)Search Engine Optimization (SEO). Penerbit Rainaldo M, Wibawa BM, Rahmawati Y. Yang Dipublikasikan Pada Jurnal

Search Engine Optimization (SEO) merupakan sebuah cara, teknik dan juga bisa dikatakan sebuah seni yang digunakan dalam hal mendesain, mengembangkan, memodifikasi dan membangun sebuah halaman website yang memiliki tingkat visibilitas serta peringkat yang tinggi dalam hasil pencarian.[4]

\subsection{SEARCH ENGINE OPTIMIZATION (SEO) MENGGUNAKAN METODE WHITE HAT SEO UNTUK MENINGKATKAN PERINGKAT DAN TRAFIK KUNJUNGAN WEBSITE. Penerbit Himawan, Arisantoso, A. S. yang dipublikasi pada Jurnal. \\ Domain adalah nama, nama yang digunakan} suatu pemilik website atau blog agar alamat website mereka mudah dihafal. Misalnya website ini domainnya adalah tatadistro.com. Berikut beberapa nama domain yang sering digunakan tersedia diinternet. Domain ini dioperasikan dan di daftarkan dimasing negara. Di Indonesia, domain-domain ini berakhiran, .co.id, .ac.id, .go.id, .mil.id, .or.id, dan pada akhir-akhir ini ditambah dengan war.net.id, .mil.id, dan web.id. [5]

\section{METODE PENELITIAN}

Dalam melakukan penelitian ini penulis menggunakan metode penelitian sebagai berikut :

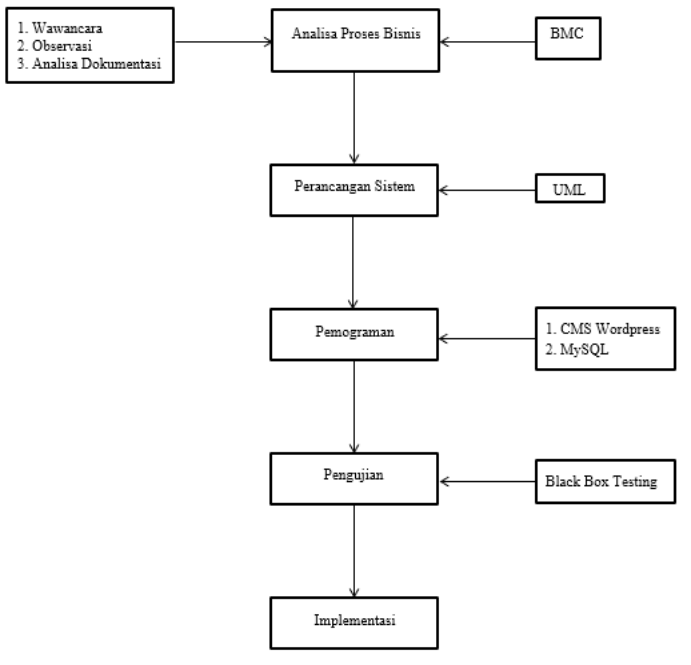

Gambar 1. Metodologi Penelitian

Pada Gambar 1 menjelaskan struktur proses yang akan dilakukan oleh peneliti dan juga alur alurnya.

\subsection{Analisa Proses Bisnis}

Dalam melakukan penelitian ini, analisa proses bisnis yang dilakukan oleh penulis adalah sebagai berikut :

Observasi, penulis mengumpulkan data-data dengan cara mengamati secara langsung pada tempat riset untuk mengetahui proses bisnis yang berjalan saat ini untuk memperoleh data secara jelas dan lengkap.

Wawancara, penulis memberikan berbagai pertanyaan kepada pemilik toko untuk mengetahui informasi mengenai masalah yang dihadapi oleh toko dan pelanggan.

Dokumentasi, penulis mengumpulkan dokumen dari Toko Danis yang berhubungan dengan objek penelitian ini, seperti data barang, harga barang serta data yang berasal dari supplier.

\subsection{Perancangan Sistem}

Pada tahapan perancangan sistem ada beberapa cara atau teknik teknik yang ada pada sebuah sistem dan disini penulis membangun sistem dengan menggunakan sebuah rancangan yaitu dengan membuat sebuah BMC, UML seperti Acivity Diagram, Use Case, Class Diagram, Sequence Diagram, dan beberapa lainnya.

\subsection{Pemrograman}

Pada tahap ini dilakukan pemrograman yang dimana penulis membuat sebuah website dengan menggunakan Content Management System (CMC) sehingga memudahkan penulis membuat sebuah website. 


\subsection{Pengujian}

Ketika penulis sudah memiliki atau sudah menyelesaikan website tersebut akan di adakan pengujian yang dilakukan dengan teknik black box testing disini akan dilakukan pengujian yang bertujuan untuk mengetahui fungsi-fungsi yang ada pada website tersebut.

\subsection{Implementasi}

Setelah semuanya sudah diselesaikan dan tidak ada kesalahan atau kekurangan pada website tersebut dan semua fungsi-fungsi pada website berjalan lancar maka penulis akan menerapkan pada Toko Danis ketika semua langkah-langkah sudah di uji dengan baik.

\section{HASIL DAN PEMBAHASAN}

4.1. Business Model Canvas

Berikut ini adalah hasil Business Model Canvas yang telah penulis buat sebagai berikut :

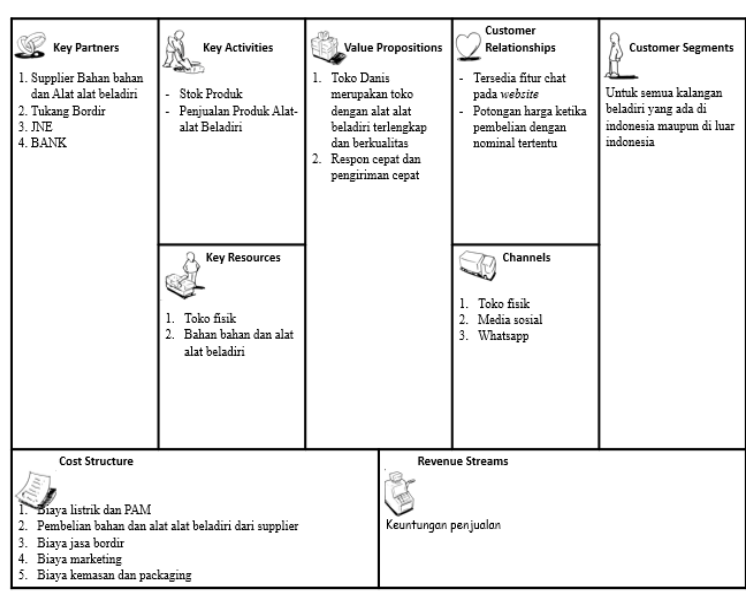

Gambar 2. Business Model Canvas

Pada Gambar 2 menjelaskan Business Model Canvas ini tentang apa saja yang ada pada toko atau perusahaan, dan juga tentang pendapatan yang di dapat oleh toko maupun perusahaan.

\subsection{Activity Diagram Sistem Usulan}

a. Proses Login

Proses Login tersebut awalan sebelum user memasuki web tersebut. Jadi setiap users harus login terlebih dahulu, supaya user bisa dashbard mengakses website Toko Danis. Pada gambar 3 menjelaskan proses login.

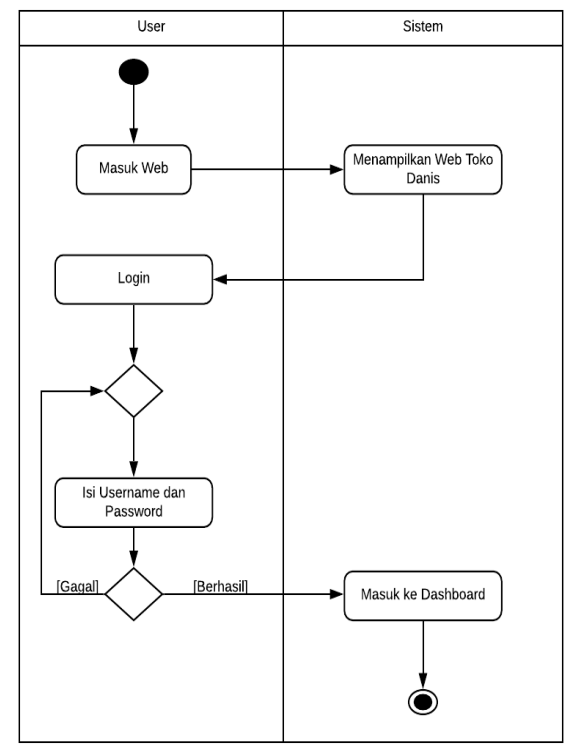

Gambar 3. Activity Diagram Proses Login

\section{b. Proses Pemesanan Barang}

Pada tahapan pertama pelanggan diharuskan untuk melakukan login di website, setelah sudah login pelanggan memilih kategori yang di inginkan setelah itu pelanggan bebas memilih barang yang ingin dia inginkan, lalu memilih jenis barang dan jumlah barang yang akan dibeli, selanjutnya dimasukkan ke keranjang belanja, jika melanjutkan belanja maka pelanggan akan memilih barang yang lainnya, lalu barang yang sudah masuk ke dalam keranjang belanja, setelah itu pelanggan mengklik checkout. Lalu pelanggan mengklik order dan sistem menyimpan data yang telah di isi pelanggan. Pada gambar 4 menggambarkan proses pemesanan barang.

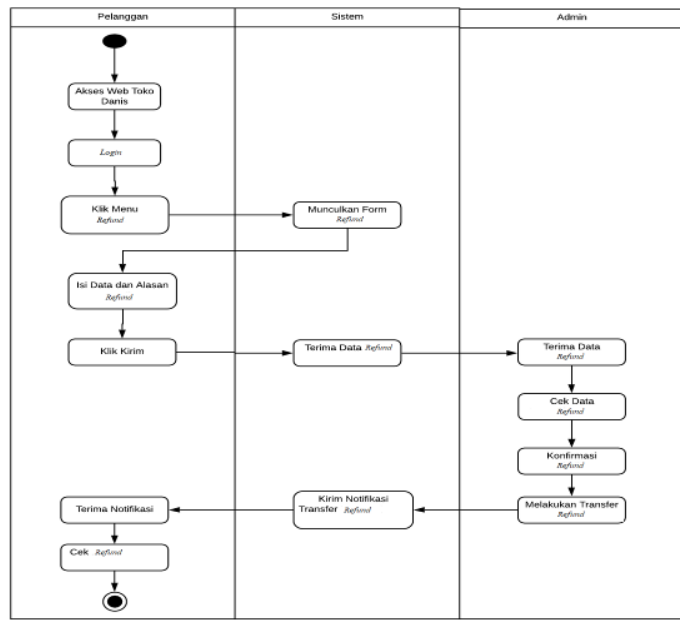

Gambar 4. Activity Diagram Proses Pemesanan Barang

c. Proses Konfirmasi Pembayaran

Pelanggan melakukan pembayaran dengan cara transfer dan bukti dari pembayaran tersebut 
disimpan terlebih dahulu, kemudian pelanggan memilih konfirmasi pembayaran. selanjutnya admin mengubah status pembayarannya dan sistem akan menyimpan data. Sehingga admin dapat mengetahui apakah customer sudah melakukan pembayaran atau belum. Pada gambar 5 menjelaskan proses konfirmasi pembayaran.

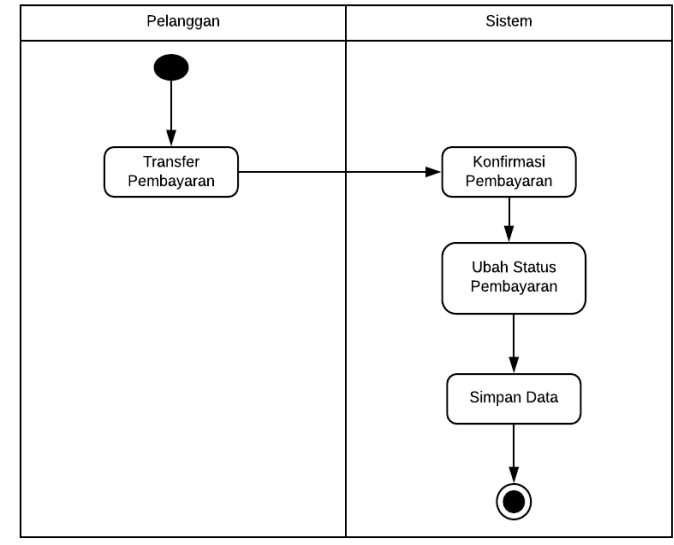

Gambar 5. Activity Diagram Proses Konfirmasi Pembayaran

\section{d. Proses Daftar Akun}

Pembeli harus mengisi data diri, alamat pembeli untuk pengiriman barang, nomor handphone dan e-mail pembeli, selanjutnya sistem akan melakukan pengecekan data dan menginput ke database, jika pelanggan sudah mempunyai akun maka dapat melakukan login.

Pada gambar 6 menjelaskan proses daftar akun.

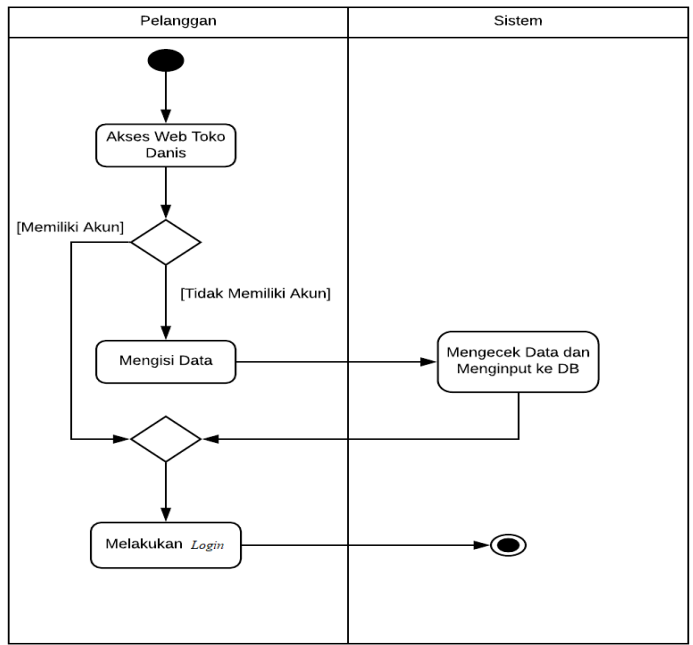

Gambar 6. Activity Diagram Proses Daftar Akun

\section{e. Proses Retur Barang}

Pelanggan melakukan retur barang jika barang yang dibeli mengalami kerusakan pada saat pelanggan mengecek barang baru diterima dalam kondisi barang yang masih dalam packaging. Sehingga pelanggan melakukan retur barang tersebut. Dan pada saat melakukan retur pelanggan harus mengisi form tentang kerusakan apa saja yang ada pada barang yang telah dikirim sehingga admin akan melalukan konfirmasi ataupun menyetujui barang tersebut dapat di retur atau tidak. Pada gambar 7 menjelaskan proses retur barang.

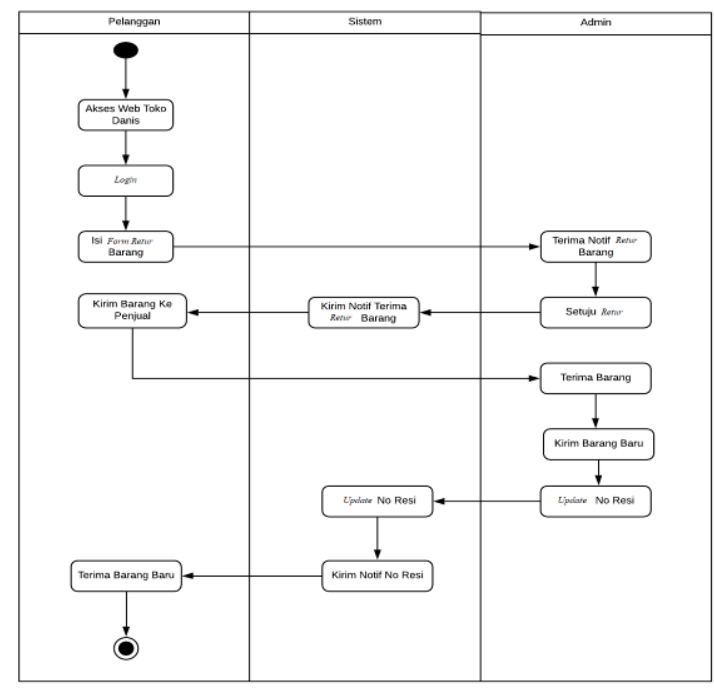

Gambar 7. Activity Diagram Proses Retur Barang

\section{f. Proses Refund}

Pelanggan dapat melakukan pengembalian dana atau uang kembali jika pelanggan tidak ingin melakukan retur barang dengan mengirim kembali barang yang diterima kepada toko. Maka pelanggan login terlebih dahulu dan memilih menu pengembalian dana, kemudian mengisi data dan alasan ingin pengembalian dana. Lalu admin akan mengecek data pengembalian dana tersebut dan melakukan transfer pengembalian dana kepada pelanggan. Pada gambar 8 menjelaskan proses refund.

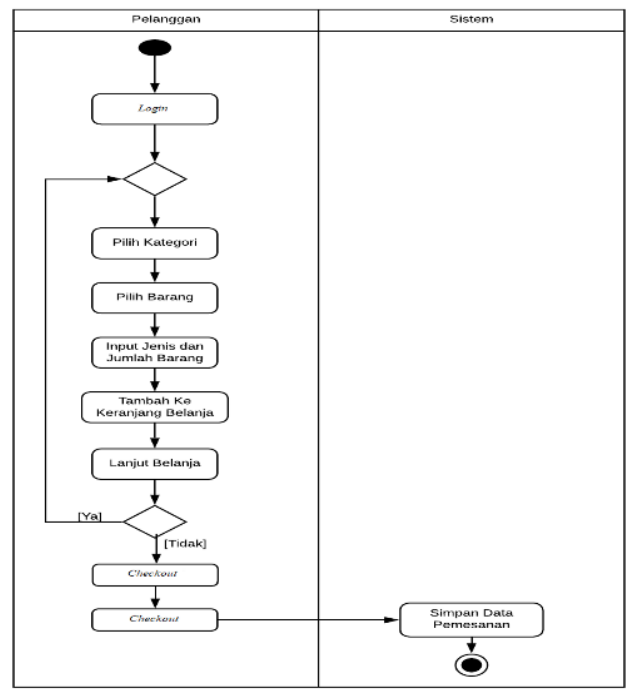

Gambar 8. Activity Diagram Refund 
g. Proses Laporan

Admin membuka website setelah itu melakukan login, selanjutnya admin memilih menu laporan dan mencetak laporan-laporan yang ingin dicetaknya. Disini admin yang dapat melihat laporan-laporan apa saja yang ada pada toko tersebut dan juga dari laporan tersebut bisa diketahui dari segi penjualan barang apa saja yang terjual, barang apa saja yang paling laris. Pada gambar 9 menjelaskan proses laporan.

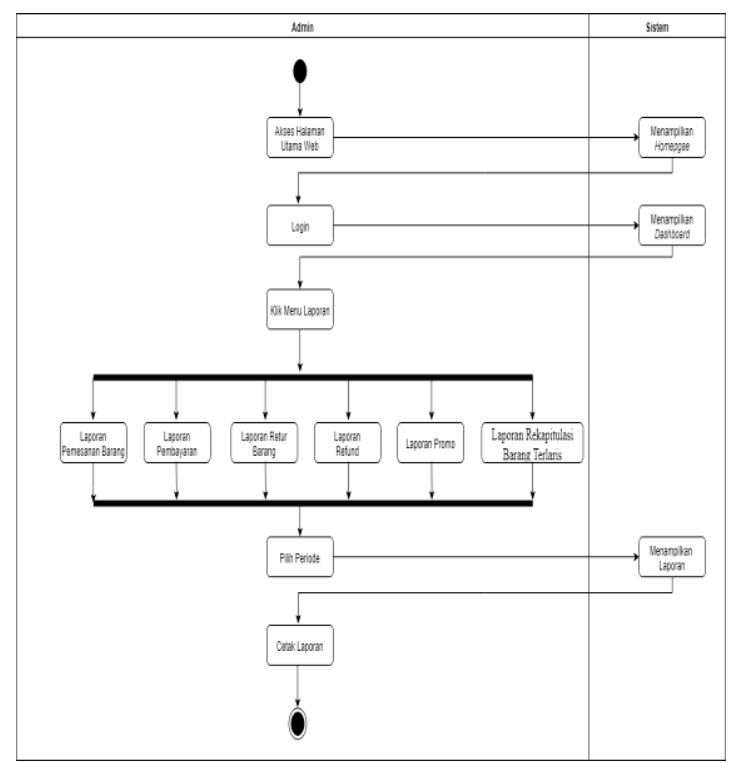

Gambar 9. Activity Diagram Laporan

\subsection{Use Case Diagram}

a. Use case diagram master

Use case ini menjelaskan apa saja yang dapat dilakukan oleh admin yang di situ ada beberapa yang dapat di edit maupun di tambahkan oleh admin tersebut. Pada gambar 10 menjelaskan use case master.

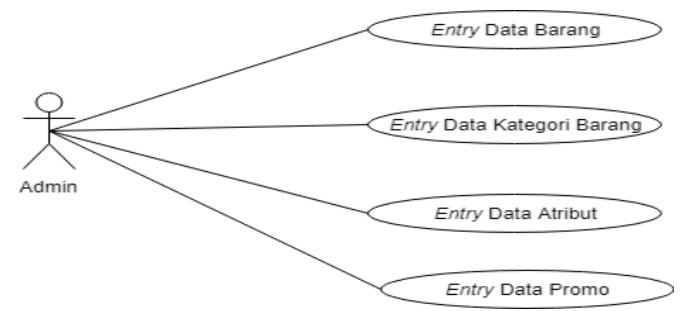

Gambar 10. Use Case Diagram Master

b. Use Case Transaksi

Disini menjelaskan tentang apa saja yang dapat dilakukan oleh admin dan pelanggan dalam hal transaksi dan juga pembayaran yang akan dilakukan pada toko tersebut. Pada gambar 11 menjelaskan use case transaksi.

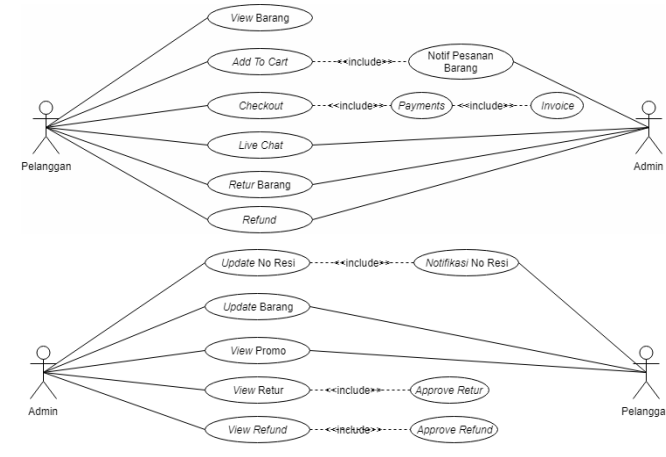

Gambar 11. Use Case Diagram Transaksi

c. Use Case Laporan

Yang dimana admin dapat melakukan cetak laporan dan hanya admin yang bisa untuk mencetak laporan-laporan yang ingin di cetak oleh nya. Pada gambar 12 menjelaskan use case laporan.

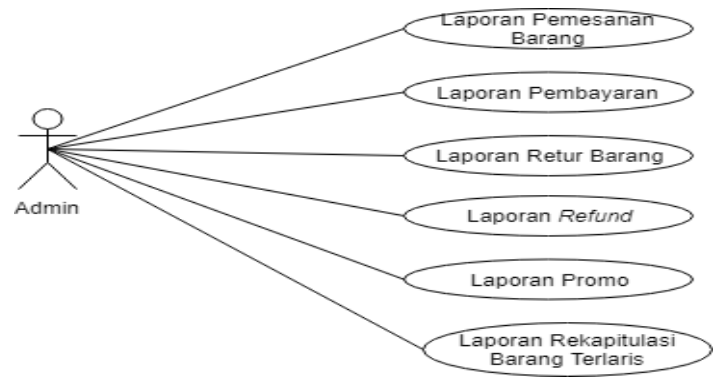

Gambar 12. Use Case Diagram Laporan

\subsection{Struktur Tampilan Menu}

Disini menjelaskan apa saja yang ada di tampilan pada halaman web toko tersebut. Sehingga pengguna dapat mengetahui letak dan posisi yang ingin dicarinya. Pada gambar 13 menjelaskan struktur tampilan menu.

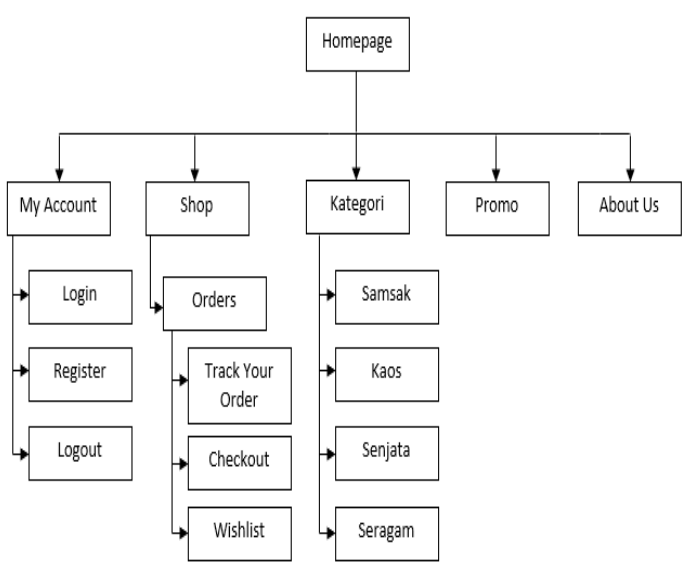

Gambar 13. Struktur Tampilan Menu 


\subsection{Rancangan Layar}

a. Rancangan Layar Menu Home

Disini untuk mengetahui tampilan tampilan apa saja yang ada pada menu home atau tampilan awal ketika pelanggan membuka website yang di kunjunginnya. Pada gambar 14 menjelaskan rancangan layar menu home.

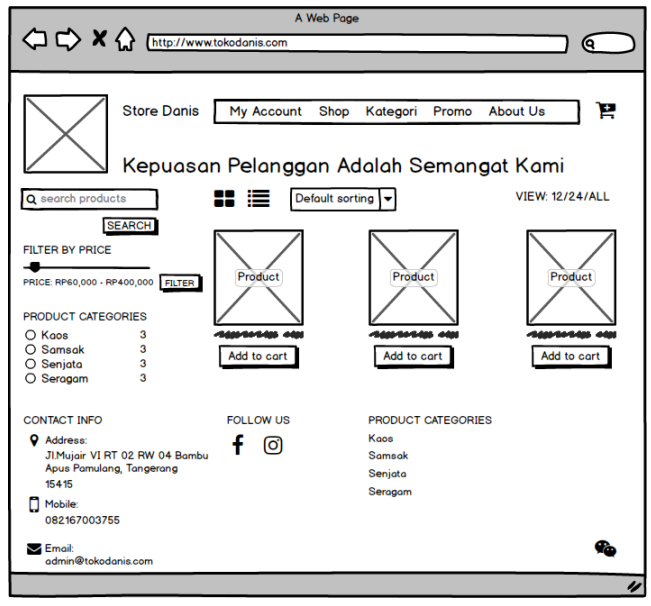

Gambar 14. Rancangan Layar Menu Home

b. Rancangan Layar Menu Login

Pada rancangan ini dibuat agar pelanggan mengetahui dimana pelanggan harus melakukan login pada website tersebut. Pada gambar 15 menjelaskan rancangan layar menu login.

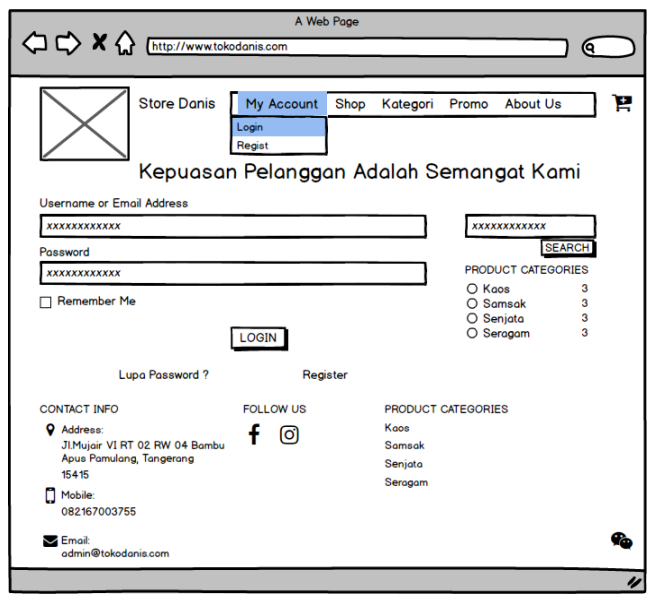

Gambar 15. Rancangan Layar Menu Login

c. Rancangan Layar Menu About Us

Disini pelanggan dapat melihat pemberitahuan apa saja yang ada pada toko atau website. Dan dapat juga melihat cara cara dan jam kerja pada toko tersebut. Pada gambar 16 menjelaskan rancangan layar menu about us.

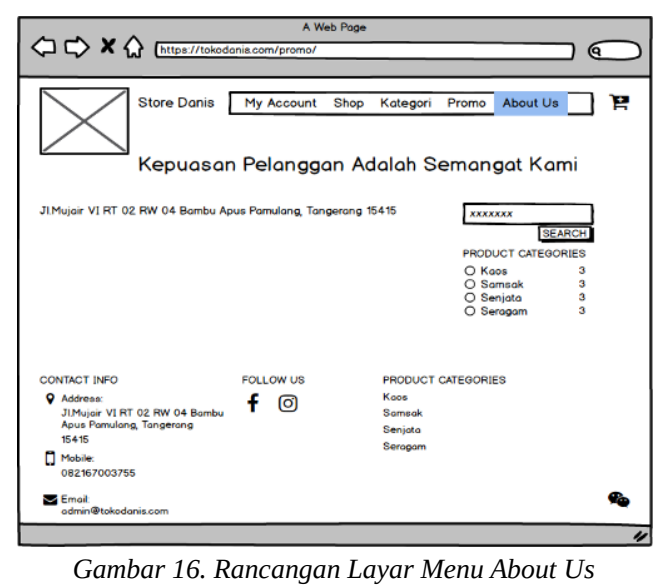

\subsection{Strategi SEO dan Marketing}

Dalam penggunaan SEO ada beberapa cara agar toko kita bisa tampil pada halaman di google dan terindeks oleh google.

1. Nama Produk dan Kata Kunci

Dalam menentukan nama produk dan kata kunci tidak bisa kita asal mengisinya. Kita juga harus mengetahui apa saja yang di cari oleh pelanggan. Jadi ketika pelanggan ingin mencari barang ataupun produk yang ingin di pesan nya, itu akan muncul produk ataupun toko kita di google. Pada gambar 17 menjelaskan kata kunci pada seo.

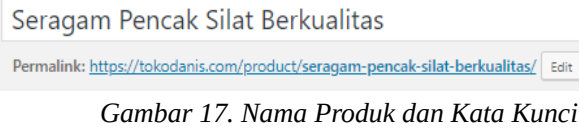

\section{Meta Description}

Meta Description digunakan oleh mesin pencari untuk menentukan apakah Meta Description relevan dengan deskripsi produk atau halaman website yang dibuat. Untuk membuat Meta Description pakailah kata-kata yang dapat menjelaskan arti dari sebuah halaman website yang akan dibuat dan pakai bahasa yang singkat dan jelas. Menempatkan nama produk pada Meta Description akan membantu mesin pencari untuk menemukan website. Pada gambar 18 menjelaskan meta description pada seo .

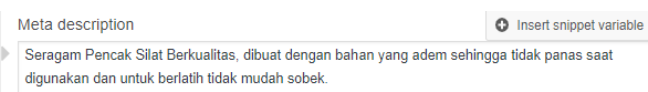

Gambar 18. Meta Description

\section{Marketing}

Dengan cara membuat iklan maupun pemasaran lewat media sosial seperti facebook, instagram dan sosial media lainnya. Dengan adanya 
marketing dalam sebuah web site penjualan dan minat pelanggan semakin tinggi.

\section{KESIMPULAN}

Berdasarkan hasil analisa pada Toko Danis, maka dapat ditarik kesimpulan sebagai berikut :

a. Dengan adanya Penerapan E-Commerce pada Toko Danis diharapkan dapat mempermudah customer dalam mengetahui produk apa saja yang terbaru.

b. Dengan dibuatnya Website untuk Toko Danis customer dapat mengetahui promo yang terdapat pada toko.

\section{DAFTAR PUSTAKA}

[1] Haerulah, E., \& Ismiyatih, S. (2017). APLIKASI E COMMERCE PENJUALAN SOUVENIR PERNIKAHAN PADA TOKO “ XYZ ,” vol.4, no.1,pp.43-47, Juni 2017.

[2] Hastanti, R. P., Eka, B., Indah, P., \& Wardati, U. (2015). Sistem Penjualan Berbasis Web ( ECommerce ) Pada Tata Distro Kabupaten Pacitan, vol.3, no.2, pp.1-9, Juli 2015.

[3] Himawan, Arisantoso, A. S. (2017). SEARCH ENGINE OPTIMIZATION (SEO) MENGGUNAKAN METODE WHITE HAT SEO UNTUK MENINGKATKAN PERINGKAT DAN TRAFIK KUNJUNGAN WEBSITE, vol 3, pp.783-790, Oktober 2017.

[4] Rainaldo, Wibawa.BM, Rahmawati.Y, M. (2017). Analisis Business Model Canvas Pada Operator Jasa Online Ride-Sharing, vol 6, no.2, pp. 2-6, Agustus 2017.

[5] Wardati, U. (2018). Konsep E-Commerce Penjualan Pada Toko Banu, Vol.2, Juli 2013. 